\title{
The association between soya consumption and serum thyroid-stimulating hormone concentrations in the Adventist Health Study-2
}

\author{
Serena Tonstad ${ }^{1, *} \uparrow$, , Karen Jaceldo-Siegl ${ }^{1}$, Mark Messina ${ }^{1}$, Ella Haddad ${ }^{1}$ and \\ Gary E Fraser ${ }^{2}$ \\ ${ }^{1}$ Center for Nutrition, Healthy Lifestyle and Disease Prevention, School of Public Health, Loma Linda University, \\ 24951 N Circle Drive, Nichol Hall Room 1519, Loma Linda, CA 92354, USA: ${ }^{2}$ Department of Cardiology, \\ School of Medicine, Loma Linda University, Loma Linda, CA, USA
}

Submitted 2 March 2015: Final revision received 12 August 2015: Accepted 9 September 2015: First published online 9 October 2015

\begin{abstract}
Objective: Consumers may choose soya foods as healthful alternatives to animal products, but concern has arisen that eating large amounts of soya may adversely affect thyroid function. The present study aimed to examine the association between soya food consumption and serum thyroid-stimulating hormone (TSH) concentrations in North American churchgoers belonging to the Seventh-day Adventist denomination that encourages vegetarianism.

Design: Participants completed six repeated 24 h dietary recalls within a 6-month period. Soya protein and soya isoflavone intakes were estimated, and their relationships to TSH concentrations measured at the end of 6 months were calculated using logistic regression analyses.

Setting: Calibration sub-study of the Adventist Health Study-2.

Subjects: Women ( $n$ 548) and men ( $n$ 295) who were not taking thyroid medications. Results: In men, age and urinary iodine concentrations were associated with high serum TSH concentrations ( $>5 \mathrm{mIU} / \mathrm{l}$ ), while among women White ethnicity was associated with high TSH. In multivariate models adjusted for age, ethnicity and urinary iodine, soya isoflavone and protein intakes were not associated with high TSH in men. In women higher soya isoflavone consumption was associated with higher TSH, with an adjusted odds ratio (highest $v$. lowest quintile) of 4.17 (95\% CI $1.73,10 \cdot 06$ ). Likewise, women with high consumption of soya protein (midpoint of highest quintile, $11 \mathrm{~g} / \mathrm{d}$ ) $v$. low consumption (midpoint of lowest quintile, $0 \mathrm{~g} / \mathrm{d}$ ) carried increased odds of high TSH (OR $=2 \cdot 69$; $95 \%$ CI $1 \cdot 34,5 \cdot 30)$.

Conclusions: In women high consumption of soya was associated with elevated TSH concentrations. No associations between soya intake and TSH were found in men.
\end{abstract}

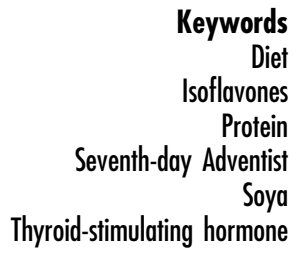

Foods made from soyabeans have been consumed in various forms by Asian populations for centuries. Among older adults in Japan mean soya protein intake is 8 to $10 \mathrm{~g} / \mathrm{d}$, whereas soya intake in the USA is $<2 \mathrm{~g} / \mathrm{d}^{(1)}$. Over the past 20 years, the popularity of soya foods has increased in non-Asian countries owing to several factors, most prominently because of consumer awareness of the potential health benefits of these foods. Another factor may be recognition of the environmental burden of eating meat and other animal products. Soya foods have been

† Current address: Oslo University Hospital, Section for Preventive Cardiology, Department of Endocrinology, Morbid Obesity and Preventive Medicine, POB 4956 Nydalen, N-0424 Oslo, Norway. proposed to alleviate menopausal symptoms, promote bone health, reduce cardiovascular risk and protect against cancer $^{(2)}$. From 1996 to 2011, soya food sales in the USA increased from \$US 1 billion to \$US $5 \cdot 2$ billion $^{(3)}$.

One of the benefits of soya foods is lowering of serum LDL cholesterol levels. Two separate mechanisms appear to be involved. Jenkins et al. estimated that when $25 \mathrm{~g}$ soya protein replaces $25 \mathrm{~g}$ protein from traditional Western sources of protein, LDL cholesterol is reduced by approximately $4 \%$ as a result of the change in the fatty acid content of the $\operatorname{diet}^{(4)}$. In addition, meta-analyses indicate that soya protein directly lowers LDL cholesterol by a similar degree ${ }^{(4)}$, which is on par with the effects of soluble fibre ${ }^{(5)}$. In 1999 the US Food and Drug 
Administration allowed a heart-health claim on soya foods that provide at least $6.25 \mathrm{~g}$ soya protein per serving ${ }^{(6)}$. Claims have been approved in ten other countries since that time and in 2014, Health Canada announced its intention to approve a health claim for soya foods based on the cholesterol-lowering effects of soya protein ${ }^{(7)}$. Recently published meta-analyses suggest soya protein may also modestly lower blood pressure ${ }^{(8,9)}$.

In addition to providing high-quality protein, soyabeans contain numerous biologically active components, such as isoflavones, that may contribute to the physiological effects of soya foods. Isoflavones have a very limited distribution in nature; among commonly consumed foods, they are found in uniquely rich amounts in soyabeans. Isoflavones are diphenolic molecules structurally similar to oestradiol and are classified as phyto-oestrogens because of their ability to exert oestrogen-like effects under certain experimental conditions. They are also classified as selective oestrogen receptor modulators which, depending upon the tissue, can function as oestrogen agonists or antagonists or even have no effects in tissues that are affected by oestrogen ${ }^{(9,10)}$. Genistein, daidzein and glycitein and their respective glycosides account for approximately 50, 40 and $10 \%$, respectively, of total soyabean isoflavone content. Isoflavones may influence disease risk through both hormonal and non-hormonal effects.

Despite the beneficial attributes of soya protein and isoflavones, eating large amounts of soya is not without some controversy ${ }^{(2)}$. There is concern, based primarily on animal studies, that isoflavones may adversely affect thyroid function, especially in susceptible individuals such as those whose thyroid function is compromised ${ }^{(11)}$. Extensive clinical work shows that in euthyroid individuals, thyroid function is not affected by isoflavone intake ${ }^{(12,13)}$ and is unlikely to be so even when iodine intake is inadequate $^{(14)}$. However, there has been little epidemiological investigation of the association of soya intake with thyroid function. This line of inquiry may provide insight beyond the clinical data by capturing effects stemming from chronic or even lifelong isoflavone intake.

Therefore, we examined the relationships between soya consumption and thyroid function in the Adventist Health Study-2 (AHS-2) cohort. The Seventh-day Adventist denomination encourages members to abstain from tobacco, drug or alcohol use, and to eat a plant-based diet when feasible. The AHS-2 cohort includes church attendees from North America, approximately half of whom are vegetarian. Consequently, intake of soya in this cohort is much greater than in the general North American population and the range of intakes observed is wider.

\section{Methods}

AHS-2 comprised more than 96000 church members aged 30 years and over, living in the USA and Canada, who completed a questionnaire about their lifestyle, medical history and demographic information. Recruitment, selection and characteristics of the cohort, which was established between 2002 and 2007, have been described previously ${ }^{(15)}$. A subset of the cohort ( $n$ 1011) took part in a calibration and validation study 1-2 years following the baseline survey ${ }^{(16)}$. These participants were randomly selected from the main cohort by church and then within the church by sex and age, with the aim of over-sampling Blacks to achieve approximately equal numbers of each ethnicity. The duration of the calibration study was 9-12 months. The study was approved by the institutional review board of Loma Linda University and all participants provided written informed consent.

Demographic characteristics of participants in the calibration study were representative of the entire cohort with regard to sex, age and education ${ }^{(16)}$. In the current analyses, valid data from 965 participants in the calibration study were available. Those taking thyroid medications were excluded ( $n$ 61), as were those with missing data ( $n$ 61). Users of thyroid medications did not differ from non-users with regard to dietary intake of soya protein or isoflavones (data not shown).

Participants provided three variably timed $24 \mathrm{~h}$ dietary recalls (representing one Saturday, one Sunday and one weekday intake) during the first two months of the calibration study ${ }^{(16)}$. The recalls were repeated approximately 6 months later, giving a total of six $24 \mathrm{~h}$ recalls for each participant. In the 6-month interval participants completed a self-administered FFQ covering their dietary intake within the past year. The FFQ is a quantitative instrument consisting of 204 foods, fifty-four questions about food preparation and forty-six fields for open-ended questions. The FFQ was designed to comprehensively cover foods commonly eaten by North American Seventh-day Adventists, including soya-based foods and drinks, and later modified to also comprise foods specific to Black Adventists ${ }^{(16)}$. The FFQ specifically queried thirty-four commercially prepared vegetarian meat analogues, fifteen soya beverages and one tofu/soyabean product. Nutrient composition of foods, including amounts of soya protein and isoflavones reported in the recalls and FFQ, were based on the Nutrition Data System for Research (NDSR) 5.0_35 database provided by the Nutrition Coordinating Center, University of Minnesota (Minneapolis, MN, USA). For foods not in the database, recipes were created and nutrition information relating to these foods was obtained from the US Department of Agriculture, manufacturers and other published data. The detailed procedures for the $24 \mathrm{~h}$ dietary recalls and FFQ have been described previously ${ }^{(16)}$. Analysis of correlation coefficients between the FFQ and the $24 \mathrm{~h}$ recall nutrient and food intakes has been previously published ${ }^{(17)}$. For soya protein the de-attenuated correlations were 0.63 (95\% CI 0.58, 0.68) for Whites and $0.40(95 \%$ CI $0.32,0.48)$ for Blacks ${ }^{(17)}$. Further study showed that soya protein estimates from the 
FFQ were also correlated with urinary excretion of daidzein, genistein and total isoflavonoids ${ }^{(18)}$. In tables, the soya isoflavone values are expressed in aglycone equivalents.

Categorizing dietary pattern was based on the FFQ. Vegans were participants who reported consuming animal products (red meat, poultry, fish, eggs, milk and dairy products $)<1$ time/month; lacto-ovo vegetarians were those who consumed dairy products and/or eggs but no fish or meat (red meat, poultry and fish $<1$ time/month); pesco vegetarians were those who consumed fish $\geq 1$ time/month and dairy products and/or eggs, but red meat or poultry $<1$ time/month; semi-vegetarians were those who consumed dairy products and/or eggs and meat $\geq 1$ time/month but $<1$ time/week; and omnivores were those who consumed animal products (red meat, poultry, fish, eggs, milk and dairy products) $>1$ time/ week. Demographics, current health and medical history data were obtained by questionnaire at baseline. Data on medication use were obtained either from the baseline questionnaire or the dietary recalls.

During the 6-month interval between the dietary recalls, participants attended a local study clinic. At the visit they completed questionnaires regarding diet and physical activity and provided fasting samples of blood and overnight urine. Body height and weight were measured, and BMI was calculated. Serum thyroid-stimulating hormone (TSH) concentrations were measured using immunoassay methodology at the Loma Linda University Medical Center clinical laboratory. Twelve-hour overnight urine collections were completed for analysis of urinary iodine using the ammonium persulfate method ${ }^{(19)}$ with an intra-assay CV of $5.07 \%$.

\section{Statistics}

Variables not normally distributed were log-transformed, including soya isoflavones and soya protein and serum TSH concentrations. Demographic characteristics, BMI, dietary variables and biological analytes according to sex are presented as means and standard deviations or as percentages, and were compared across groups using ANOVA or the $\chi^{2}$ test. The descriptive statistics showed possible sex differences. Thus, further analyses first included women and men combined with tests for interaction. These analyses indicated interactions between sex and effect $(P<0 \cdot 05)$. We then conducted sex-divided analyses. Logistic regression analyses that predicted the odds of TSH $>5.0 \mathrm{mIU} / 1$ separately as a function of each of soya isoflavone intake and soya protein intake, as measured by the repeated $24 \mathrm{~h}$ dietary recalls, were performed adjusting for age, ethnicity and urinary iodine. These treated the isoflavones as a continuous variable, and based on the $\beta$ coefficient, median values of upper and lower quintiles of intake are compared as odds ratios. Ninety-five per cent confidence intervals for odds ratios were computed. We additionally performed analyses where we adjusted for dietary variables including carotenoids, saturated fat, fibre and energy from dairy - these adjustments did not change the magnitudes of the odds ratios (data not shown). Deviance statistics were tested on all models and there was no evidence of poor fit. In a sensitivity analysis we redid all of the analyses using data from the FFQ. These results showed similar associations between soya isoflavones and TSH concentrations and soya protein and TSH concentrations as results using the repeated $24 \mathrm{~h}$ recalls (data not shown). The results using the repeated $24 \mathrm{~h}$ recalls are presented as in general repeated dietary recalls are assumed to be more valid than FFQ data ${ }^{(20,21)}$. We conducted a sensitivity analysis excluding thirteen women and two men with previously reported hypothyroidism and the main effects were not changed (data not shown). The analyses were performed using the statistical software package SAS version 9.4 and code written in the $\mathrm{R}$ language.

\section{Results}

The population included in our study had a very low prevalence of current smoking $(<2 \%)$ and only $4 \%$ currently used alcohol (data not shown). Mean TSH levels for the entire sample were $2.6 \mathrm{mIU} / \mathrm{l}$ (range 0.005-37.2 mIU/1); for participants with high TSH $(>5 \mathrm{mIU} / \mathrm{l})$ the mean was $7.99 \mathrm{mIU} / \mathrm{l}$ (range $5.05-37.2 \mathrm{mIU} / \mathrm{l}$ ). Table 1 shows demographic and dietary characteristics of participants according to sex and TSH concentration. Participants with high TSH tended to be older, were more likely of nonBlack ethnicity, had lower BMI (men) and were more likely to be vegan (women) or lacto-ovo vegetarians than those with normal TSH concentrations. Energy intakes were statistically significantly higher in men than in women, while soya protein and isoflavone intakes were higher in women with high TSH compared with men with high TSH. Intake of supplemental isoflavones did not differ between groups and was generally low. Urinary iodine excretion did not differ between women with normal or high TSH, while men with high TSH had higher urinary iodine excretion than men with normal TSH. Of forty-three women with high TSH, thirteen had reported diagnosed hypothyroidism in an earlier questionnaire within 3 years of the study. Of twenty-three men with high TSH, only two had reported diagnosed hypothyroidism in the earlier questionnaire. Table 2 shows medians and upper boundaries for quintiles of soya isoflavone and protein intakes according to sex, illustrating the wide range of intakes exhibited.

As shown in Table 3, soya isoflavone intakes were associated with higher odds of high TSH concentrations in women but not in men. Thus, for women there is an odds ratio of 4.17 comparing the highest quintile with the lowest. Table 4 shows similar results regarding soya protein intakes. Other analyses that placed all isoflavone components in the same model as separate variables 
Table 1 Demographic characteristics, soya protein and soya isoflavone intakes (dietary and supplemental), and urinary iodine concentration according to sex and TSH concentration (normal, $\leq 5 \mathrm{mlU} / \mathrm{l}$; high, $>5 \mathrm{mlU} / \mathrm{l}$ ) among participants (548 women and $295 \mathrm{men}$ ) of the Adventist Health Study-2

\begin{tabular}{|c|c|c|c|c|c|c|c|c|c|}
\hline & \multicolumn{4}{|c|}{ Women } & \multicolumn{4}{|c|}{ Men } & \multirow[b]{3}{*}{$P$ value } \\
\hline & \multicolumn{2}{|c|}{ Normal TSH } & \multicolumn{2}{|c|}{ High TSH } & \multicolumn{2}{|c|}{ Normal TSH } & \multicolumn{2}{|c|}{ High TSH } & \\
\hline & $n$ or Mean & SD or $\%$ & $n$ or Mean & SD or $\%$ & $n$ or Mean & SD or $\%$ & $n$ or Mean & SD or $\%$ & \\
\hline$n$ & 505 & - & 43 & - & 274 & - & 21 & - & - \\
\hline $\begin{array}{l}\text { Age (years), mean and SD } \\
\text { Ethnicity, } n \text { and } \%\end{array}$ & $56 \cdot 6$ & $13 \cdot 2$ & $60 \cdot 9$ & $15 \cdot 2$ & $58 \cdot 1$ & $13 \cdot 1$ & $70 \cdot 3$ & $11 \cdot 5$ & $\begin{array}{l}<0.001 \\
<0.001\end{array}$ \\
\hline Black & 248 & $49 \cdot 1$ & 11 & $25 \cdot 6$ & 120 & 43.8 & 3 & $14 \cdot 3$ & \\
\hline White & 257 & $50 \cdot 9$ & 32 & $74 \cdot 4$ & 154 & $56 \cdot 2$ & 18 & $85 \cdot 7$ & \\
\hline $\begin{array}{l}\text { BMI }\left(\mathrm{kg} / \mathrm{m}^{2}\right) \text {, mean and SD } \\
\text { Dietary pattern, } n \text { and } \%\end{array}$ & 28.5 & 6.9 & $28 \cdot 1$ & $9 \cdot 4$ & $27 \cdot 5$ & $5 \cdot 3$ & $25 \cdot 4$ & 3.8 & $\begin{array}{l}0.07 \\
0.01\end{array}$ \\
\hline Vegan & 48 & 9.5 & 10 & $23 \cdot 3$ & 20 & $7 \cdot 3$ & 1 & 4.8 & \\
\hline Lacto-ovo vegetarian & 124 & $24 \cdot 6$ & 16 & $37 \cdot 2$ & 86 & 31.4 & 9 & 42.9 & \\
\hline Pesco vegetarian & 61 & $12 \cdot 1$ & 5 & $11 \cdot 6$ & 30 & $10 \cdot 9$ & 1 & $4 \cdot 8$ & \\
\hline Semi-vegetarian & 22 & 4.4 & 2 & 4.7 & 16 & $5 \cdot 8$ & 0 & 0.0 & \\
\hline Omnivore & 250 & 49.5 & 10 & $23 \cdot 3$ & 122 & 44.5 & 10 & $47 \cdot 6$ & \\
\hline \multicolumn{10}{|c|}{ Energy and soya intakes (mean of six $24 \mathrm{~h}$ recalls), mean and SD } \\
\hline Total energy (kJ/d) & 5874 & 1803 & 6456 & 1661 & 7489 & 2318 & 7293 & 1854 & $<0.001$ \\
\hline Total energy $(\mathrm{kcal} / \mathrm{d})$ & 1404 & 431 & 1543 & 397 & 1790 & 554 & 1743 & 443 & $<0.001$ \\
\hline Soya protein $(\mathrm{g} / \mathrm{d})$ & $2 \cdot 3$ & $3 \cdot 1$ & 4.7 & 4.5 & $2 \cdot 8$ & 3.7 & $2 \cdot 7$ & 3.6 & $<0.001$ \\
\hline Soya isoflavones $(\mathrm{mg} / \mathrm{d})$ & $8 \cdot 3$ & 13.4 & $15 \cdot 4$ & $16 \cdot 0$ & $10 \cdot 1$ & $17 \cdot 2$ & $7 \cdot 6$ & $8 \cdot 0$ & 0.015 \\
\hline Dietary & $7 \cdot 4$ & $10 \cdot 8$ & $15 \cdot 4$ & $16 \cdot 1$ & $9 \cdot 1$ & $12 \cdot 9$ & $7 \cdot 6$ & $8 \cdot 0$ & $<0.001$ \\
\hline Supplemental & 0.9 & $7 \cdot 5$ & 0.0 & 0.0 & 1.0 & $10 \cdot 9$ & 0.04 & 0.3 & 0.9 \\
\hline Supplements taken, $n$ and $\%$ & 24 & 4.8 & 1 & $2 \cdot 3$ & 3 & $1 \cdot 1$ & 0 & 0.0 & \\
\hline Urinary iodide $(\mu \mathrm{g} / \mathrm{ml})$, mean and SD & 0.13 & 0.13 & 0.13 & $0 \cdot 16$ & 0.14 & 0.12 & 0.22 & 0.20 & 0.008 \\
\hline
\end{tabular}

TSH, thyroid-stimulating hormone.

${ }^{*} P$ values are for comparisons across the groups using ANOVA or the $x^{2}$ test.

Table 2 Quintile distribution of soya isoflavone and soya protein intakes according to six repeated $24 \mathrm{~h}$ recalls among participants (295 men and 548 women) of the Adventist Health Study-2

\begin{tabular}{|c|c|c|c|}
\hline & \multicolumn{3}{|c|}{ Median, upper boundary of quintile } \\
\hline & \multicolumn{2}{|c|}{ Soya isoflavones $(\mathrm{mg} / \mathrm{d})$} & \multirow{2}{*}{$\frac{\text { Soya protein }(\mathrm{g} / \mathrm{d})}{\text { Dietary }}$} \\
\hline & Dietary & Dietary + supplemental & \\
\hline \multicolumn{4}{|l|}{ Men } \\
\hline 1 & $0.006,0.13$ & $0.006,0.13$ & $0.008,0.08$ \\
\hline 2 & $0.57,1.66$ & $0.57,1.68$ & $0.29,0.67$ \\
\hline 3 & $4.61,6.98$ & $4.69,7.09$ & $1.51,2.29$ \\
\hline 4 & $9.86,15.07$ & $10 \cdot 18,15 \cdot 51$ & $3.32,4.54$ \\
\hline 5 & $23.58,69.85$ & $25 \cdot 46,180 \cdot 35$ & $6 \cdot 91,22 \cdot 38$ \\
\hline \multicolumn{4}{|c|}{ Women } \\
\hline 1 & $0.001,0.03$ & $0.002,0.04$ & $0.004,0.03$ \\
\hline 2 & $0.35,1.14$ & $0.41,1.25$ & $0.15,0.50$ \\
\hline 3 & $2 \cdot 76,5 \cdot 35$ & $3 \cdot 10,5 \cdot 85$ & $0.91,1.72$ \\
\hline 4 & $8.54,14.52$ & $9.37,15.48$ & $2 \cdot 81,4 \cdot 45$ \\
\hline 5 & $21.93,83.68$ & $25.50,260.54$ & $6.92,24.02$ \\
\hline
\end{tabular}

showed that no one isoflavone stood out as a predictor of TSH. In univariate analyses, each isoflavone largely stood for the whole, given that they were closely interrelated (data not shown).

\section{Discussion}

The findings show that in women the highest quintile of soya food consumption was associated with elevated TSH concentrations. When soya protein was used as an index of soya consumption, the odds ratio was somewhat lower than when the soya isoflavone index was used but the confidence intervals overlapped. We found no relationship between soya consumption and TSH concentrations in men.

One of the notable features of the present study was the wide range of dietary characteristics of the population, consistent with their eating patterns ranging from strict avoiders of animal foods to non-vegetarians. The consumption of soya foods also exhibited extreme variation, ranging from practically no soya food consumption in the lowest quintile to over 100-fold greater intake in the highest quintile. This variation made it possible to study associations with thyroid function across a wide range of soya intakes. Most Western populations exhibit isoflavone intakes of $<3 \mathrm{mg} / \mathrm{d}^{(22)}$ which was typical of the two lowest quintiles observed in the present study. The isoflavone intake of the high soya consumers was approximately double the mean intake among older Japanese, typically about $40 \mathrm{mg} / \mathrm{d}^{(22)}$. A further strength of the study was that the population made it possible to avoid the possible confounding effects of smoking ${ }^{(23)}$ and excess alcohol ${ }^{(24)}$ on dietary choices and thyroid function, both of which have been shown to affect thyroid function.

The idea that soya may influence thyroid function originated over eight decades ago when marked thyroid enlargement was seen in rats fed raw soyabeans ${ }^{(25)}$. Much more recently, soya isoflavones were shown to inhibit 
Table 3 Odds ratios and $95 \%$ confidence intervals for the association between soya isoflavones and TSH concentrations $>5 \mathrm{mlU} / \mathrm{l} v$. $\leq 5 \mathrm{mlU} / \mathrm{l}$, controlling for demographic characteristics and urinary iodine concentration, among participants (295 men and 548 women) of the Adventist Health Study-2

\begin{tabular}{llll}
\hline & OR & $95 \% \mathrm{Cl}$ & $P$ value \\
\hline Men & & & $<0.001$ \\
Age (10-year intervals) & 2.05 & $1.38,3.03$ & 0.2 \\
Ethnicity (Black $v$. White) & 0.38 & $0.10,1.43$ & 0.009 \\
Urinary iodine $(0.1 \mu \mathrm{g} / \mathrm{ml}$ intervals) & 1.47 & $1.10,1.97$ & 0.9 \\
Soya isoflavones (total) & 1.05 & $0.27,4.07$ & 0.3 \\
Women & & & 0.03 \\
Age (10-year intervals) & 1.14 & $0.21,0.92$ & 0.5 \\
Ethnicity (Black $v$. White) & 0.44 & $0.86,1.37$ & 0.001 \\
Urinary iodine $(0 \cdot 1 \mu \mathrm{g} / \mathrm{ml}$ intervals) & 1.09 & $1.73,10.06$ & \\
Soya isoflavones (total) & 4.17 & & \\
\hline
\end{tabular}

$\mathrm{TSH}$, thyroid-stimulating hormone.

${ }^{*}$ For soya isoflavones, the highest and lowest quintiles are compared. Midpoints of the lowest and highest quintiles of soya isoflavones were respectively 0.006 and $25.46 \mathrm{mg} / \mathrm{d}$ for men and 0.002 and $25.05 \mathrm{mg} / \mathrm{d}$ for women.

Table 4 Odds ratios and $95 \%$ confidence intervals for the association between soya protein and TSH concentrations $>5 \mathrm{mlU} / \mathrm{l} v . \leq 5 \mathrm{mlU} / \mathrm{l}$, controlling for demographic characteristics and urinary iodine concentration, among participants (295 men and 548 women) of the Adventist Health Study-2

\begin{tabular}{llll}
\hline & OR & $95 \% \mathrm{Cl}$ & $P$ value \\
\hline Men & & & \\
Age (10-year intervals) & 2.04 & $1.38,3.03$ & $<0.001$ \\
Ethnicity (Black $v$. White) & 0.39 & $0.10,1.43$ & 0.2 \\
Urinary iodine $(0.1 \mu \mathrm{g} / \mathrm{ml}$ intervals) & 1.47 & $1.10,1.97$ & 0.009 \\
Soya protein* & 1.06 & $0.31,3.69$ & 0.9 \\
Women & & & 0.2 \\
Age (10-year intervals) & 1.16 & $0.91,1.48$ & 0.03 \\
Ethnicity (Black $v$. White) & 0.44 & $0.21,0.92$ & 0.6 \\
Urinary iodine $(0.1 \mu \mathrm{g} / \mathrm{ml}$ intervals) & 1.06 & $1.34,1.34$ & 0.005 \\
Soya protein* & 2.69 & & \\
\hline
\end{tabular}

TSH, thyroid-stimulating hormone.

${ }^{*}$ For soya protein, the highest and lowest quintiles were compared. Midpoints of the lowest and highest quintiles of soya protein were respectively 0.008 and $6.91 \mathrm{~g} / \mathrm{d}$ for men and 0.004 and $6.92 \mathrm{~g} / \mathrm{d}$ for women.

thyroid peroxidase in vitro and in vivo in rats although rat thyroid function remained normal ${ }^{(26)}$. Others have reported that in rats while soya isoflavones inhibit synthesis of thyroglobulin and thyroid hormones, availability of thyroid hormone in peripheral tissues may increase ${ }^{(27)}$. The observation that people living in Asian countries have consumed soya foods for centuries with no perceptible thyrotoxic effects suggests their safety in the general population. However, certain subgroups may be susceptible to the effects of excess soya, in particular individuals with subclinical hypothyroidism (TSH level $>5 \cdot 0$ and $<10 \cdot 0 \mathrm{mIU} / \mathrm{l})^{(12,28)}$.

The current study found an association between soya food intake and elevated serum TSH only in women. Women have more prevalent thyroid disease than men, especially during perimenopause and menopause, and may be more susceptible to effects of goitrogens or antithyroid environmental factors ${ }^{(29)}$. A systematic review and analysis published in 2009 found that isoflavone-rich soya products had negligible effects on sex hormones in pre- and postmenopausal women ${ }^{(10)}$. Furthermore, no effects on thyroid function (TSH and thyroxine) in postmenopausal women were seen. There were insufficient data to assess effects in premenopausal women ${ }^{(10)}$. Studies published subsequent to that meta-analysis have confirmed the notion of general safety. To this point, administration of $54 \mathrm{mg}$ of genistein aglycone daily for up to 3 years in osteopenic postmenopausal women did not affect serum thyroid hormones or autoantibodies compared with placebo ${ }^{(13)}$. Also, a placebo-controlled double-blind clinical trial found no changes in thyrotropin or thyroid antibodies after administration of $200 \mathrm{mg}$ of isoflavone daily for 2 years ${ }^{(30)}$. Another study found that although $80 \mathrm{mg}$ of isoflavones taken daily by menopausal women resulted in a slight increase in the ratio of triiodothyronine to thyroxine, there was change in other measures of thyroid function ${ }^{(14)}$.

In oophorectomized Indian women, no effect of daily administration of $75 \mathrm{mg}$ of soya isoflavones for 12 weeks was seen on serum thyroid function parameters or anti-thyroid peroxidase antibodies, although a modest decrease in serum triiodothyronine was noted ${ }^{(31)}$. Likewise, in a 3-year study, postmenopausal women given 80 or $120 \mathrm{mg}$ of soya isoflavones daily showed no changes in thyroid function ${ }^{(32)}$. The authors of these recent publications have concluded that genistein and probably other 
isoflavones appear to show a good profile of safety in regard to thyroid function ${ }^{(33)}$.

We are aware of a single study of isoflavone supplementation conducted in patients with subclinical hypothyroidism. In that cross-over study, sixty middleaged mostly female patients were randomly assigned to low-dose isoflavone supplementation $(2 \mathrm{mg} / \mathrm{d})$ or highdose supplementation $(16 \mathrm{mg} / \mathrm{d})$. After 8 weeks there was a threefold increased risk of overt hypothyroidism in the high-dose group ${ }^{(34)}$. Our cross-sectional findings may be in line with that study, suggesting an association between subclinical hypothyroidism and soya intake in women.

While the high soya food consumers in the current study reported levels of isoflavones that were very high compared with Western and even Asian populations, these levels were not higher than those reported in several of the randomized studies. These intakes may have been maintained for several years. However, the dietary methods may not correctly reflect long-term food intakes, and data regarding change in diet or duration of current soya food intakes were not available. Thus, the findings may indicate that study of longer duration of use of soya foods in Western populations may be needed.

We found similar results when findings were analysed according to soya protein intake. Isoflavone contents of foods differ as each gram of soya protein in traditional soya foods provides about 3-4 mg isoflavones, whereas products made using more processed forms of soya such as isolated soya protein typically provide much lower amounts of isoflavones per gram of protein ${ }^{(12)}$.

Women consuming a vegan diet were more likely than women consuming the other diets to exhibit high serum TSH concentrations. This observation is in contrast with our earlier publication showing no increase in reported hypothyroidism among vegans in the AHS-2 population ${ }^{(35)}$. It remains possible that diet is changed after a diagnosis of hypothyroidism or that persons following a vegan diet are less likely than those eating usual diets to attend medical care and be diagnosed with the condition ${ }^{(36)}$. Of the total cohort, $56 \%$ had urinary iodine concentration below $0 \cdot 1 \mu \mathrm{g} / \mathrm{ml}$, suggesting that this was a sample with relatively low iodine intake that was possibly more susceptible to the effects of soya intake on thyroid function.

\section{Study limitations}

Dietary characteristics may be associated with differences in lifestyle habits or demographic features that influence thyroid function. We adjusted for the important predictors of thyroid function, including age and ethnicity as well as iodine excretion. One possible confounder that was not measured is family history of thyroid disease, nor did we measure levels of thyroid antibodies. In addition, there was no adjustment for other dietary factors that potentially affect thyroid function such as intakes of vitamin $\mathrm{B}_{12}$, Se and cruciferous vegetables that may differ according to dietary patterns. Of course, the cross-sectional nature of this design prohibits conclusions about there being a causal basis for the observed relationship between isoflavone intake and TSH in women.

We analysed our results according to the repeated $24 \mathrm{~h}$ recall dietary data. Analyses of the food frequency data showed similar directions of associations and these associations were statistically significant in women, but not in men (data not shown). Any differences between dietary intake assessed by repeated dietary recalls or FFQ are not unexpected as they will have different validity and systematic errors. When we correlated both methods of dietary assessment to excretion of isoflavones, we could not demonstrate strong differences between the methods ${ }^{(18)}$.

\section{Conclusion}

We found that Western women who were very high consumers of soya isoflavones or soya protein had an increased risk of elevated TSH concentration $>5 \mathrm{mIU} / \mathrm{l}$. This observational finding deserves further investigation.

\section{Acknowledgements}

Financial support: The work was supported in part by the Soy Nutrition Institute. The funder had no role in the design, analysis of writing of this article. Conflict of interest: M.M. is the executive director the Soy Nutrition Institute and regularly consults for organizations that sell and/or manufacture soya foods and/or soya supplements. None of the other authors declared conflicts of interest with respect to their authorship or the publication of this article. Authorship: G.E.F. and M.M. conceived of the study; K.J.-S. and E.H. were responsible for the dietary and blood and urine analyses; G.E.F. performed the statistical analyses; S.T. and M.M. wrote the initial draft. All of the authors interpreted the data, took part in rewriting the article and have approved the final manuscript. Ethics of human subject participation: The study was approved by the institutional review board of Loma Linda University and all participants provided written informed consent.

\section{References}

1. Messina M, Nagata C \& Wu AH (2006) Estimated Asian adult soy protein and isoflavone intakes. Nutr Cancer 55, 1-12.

2. D'Adamo CR \& Sahin A (2014) Soy foods and supplementation: a review of commonly perceived health benefits and risks. Altern Ther Health Med 20, Suppl. 1, 39-51.

3. Soyfoods Association of North America (2014) Soy Products. Sales and Trends. http://www.soyfoods.org/products/salesand-trends (accessed September 2014).

4. Jenkins DJ, Mirrahimi A, Srichaikul K et al. (2010) Soy protein reduces serum cholesterol by both intrinsic and food displacement mechanisms. J Nutr 140, issue 2, 2302S-2311S. 
5. Brown L, Rosner B, Willett WW et al. (1999) Cholesterollowering effects of dietary fiber: a meta-analysis. Am J Clin Nutr 69, 30-42.

6. Food and Drug Administration, US Department of Health and Human Services (1999) Food labeling: health claims: soy protein and coronary heart disease. Final rule. Fed Regist 64, 57700-57733.

7. Benkhedda KB, Sinclair SE, Marles RJ et al. (2014) Food Risk Analysis Communication issued by Health Canada's Food Directorate. Health Canada's proposal to accept a health claim about soy products and cholesterol lowering. Int Food Risk Anal J 4, 22.

8. Dong JY, Tong X, Wu ZW et al. (2011) Effect of soya protein on blood pressure: a meta-analysis of randomized controlled trials. Br J Nutr 106, 317-326.

9. Liu XX, Li SH, Chen JZ et al. (2012) Effect of soy isoflavones on blood pressure: a meta-analysis of randomized controlled trials. Nutr Metab Cardiovasc Dis 22, 463-470.

10. Hooper L, Ryder JJ, Kurzer MS et al. (2009) Effects of soy protein and isoflavones on circulating hormone cencentrations in pre- and post-menopausal women: a systematic review and meta-analysis. Hum Reprod Update 15, 423-440.

11. Doerge D \& Chang H (2002) Inactivation of thyroid peroxidase by soy isoflavones, in vitro and in vivo. J Chromatogr B Analyt Technol Biomed Life Sci 777, 269-279.

12. Messina M \& Redmond G (2006) Effects of soy protein and soybean isoflavones on thyroid function in healthy adults and hypothyroid patients: a review of the relevant literature. Thyroid 16, 249-258.

13. Bitto A, Polito F, Atteritano M et al. (2010) Genistein aglycone does not affect thyroid function: results from a three-year, randomized, double-blind, placebo-controlled trial. J Clin Endocrinol Metab 95, 3067-3072.

14. Sosvorová L, Mikšátková P, Bičíková M et al. (2012) The presence of monoiodinated derivates of daidzein and genistein in human urine and its effect on thyroid gland function. Food Chem Toxicol 50, 2774-2779.

15. Butler T, Fraser GE, Beeson WL et al. (2008) Cohort profile: the Adventist Health Study-2 (AHS-2). Int J Epidemiol 37, 260-265.

16. Jaceldo-Siegl K, Knutsen SF, Sabaté J et al. (2010) Validation of nutrient intake using an FFQ and repeated $24 \mathrm{~h}$ recalls in black and white subjects of the Adventist Health Study-2 (AHS-2). Public Health Nutr 13, 812-819.

17. Jaceldo-Siegl K, Fan J, Sabaté J et al. (2011) Race-specific validation of food intake obtained from a comprehensive FFQ: the Adventist Health Study-2. Public Health Nutr 14, 1988-1997.

18. Jaceldo-Siegl K, Fraser GE, Chan J et al. (2008) Validation of soy protein estimates from a food-frequency questionnaire with repeated 24-h recalls and isoflavonoid excretion in overnight urine in a Western population with a wide range of soy intakes. Am J Clin Nutr 87, 1422-1427.

19. Pino S, Fang SL \& Braverman LE (1998) Ammonium persulfate: a new and safe method for measuring urinary iodine by ammonium persulfate oxidation. Exp Clin Endocrinol Diabates 106, Suppl. 3, S22-S27.

20. Fraser GE \& Shavlik DJ (2004) Correlations between estimated and true dietary intakes. Ann Epidemiol 14, 287-295.

21. Fraser GE, Butler TL \& Shavlik D (2005) Correlations between estimated and true dietary intakes: using two instrumental variables. Ann Epidemiol 15, 509-518.

22. Messina M (2010) A brief historical overview of the past two decades of soy and isoflavone research. J Nutr 140, issue 7, 1350S-1354S.

23. Wiersinga WM (2013) Smoking and thyroid. Clin Endocrinol (Oxf) 79, 145-151.

24. Rachdaoui N \& Sarkar DK (2013) Effects of alcohol on the endocrine system. Endocrinol Metab Clin North Am $\mathbf{4 2}$, 593-615.

25. McCarrison R (1933) The goitrogenic action of soy-bean and ground-nut. Indian J Med Res 21, 179.

26. Divi RL, Chang HCC \& Doerge D (1997) Anti-thyroid isoflavones from soybean: isolation, characterization, and mechanisms of action. Biochem Pharmacol 54, 1087-1096.

27. Tran L, Hammuda M, Wood C et al. (2013) Soy extracts suppressed iodine uptake and stimulated the production of autoimmunogen in rat thyrocytes. Exp Biol Med 238, 623-630.

28. Sošić-Jurjević B, Filipović B, Wirth EK et al. (2014) Soy isoflavones interfere with thyroid hormone hoemoestasis in orchidectomized middle-aged rats. Toxicol Appl Pharmacol 278, 124-134.

29. Golden SH, Robinson KA, Saldanha I et al. (2009) Clinical review: Prevalence and incidence of endocrine and metabolic disorders in the United States: a comprehensive review. J Clin Endocrinol Metab 94, 1853-1878.

30. Levis S, Strickman-Stein N, Ganjei-Azar P et al. (2011) Soy isoflavones in the prevention of menopausal bone loss and menopausal symptoms. Arch Intern Med 171, 1363-1369.

31. Mittal N, Hota D, Dutta P et al. (2011) Evaluation of effect of isoflavone on thyroid economy \& autoimmunity in oophorectomised women: a randomized, double-blind, placebo-controlled trial. Indian J Med Res 133, 633-640.

32. Alekel DL, Censchel U, Koehler KJ et al. (2015) Soy Isoflavones for Reducing Bone Loss Study: effects of a 3-year trial on hormones, adverse events, and endometrial thickness in postmenopausal women. Menopause 22, 185-197.

33. Marini H, Polito F, Adamo EB et al. (2012) Update on genistein and thyroid: an overall message of safety. Front Ednocrinol 3, 94.

34. Sathyapalan T, Manucherhri AM, Thatcher NJ et al. (2011) The effect of soy phytoestrogen supplementation on thyroid status and cardiovascular risk markers in patients with subclinical hypothyroidism: a randomized, double-blind, crossover study. J Clin Endocrinol Metab 96, 1442-1449.

35. Tonstad S, Edward N, Oda K et al. (2013) Vegan diet and hypothyroidism. Nutrients 5, 4642-4652.

36. Ibrayev Y, Oda K, Fraser GE et al. (2013) Utilization of prostate cancer screening according to dietary patterns and other demographic variables. The Adventist Health Study-2. J Cancer 4, 416-426. 